\title{
Lebers Amaurosis in Three Siblings: A case report
}

\author{
E Samaila, T Ndife, AF Mahmud-Ajeigbe \\ Department of Ophthalmology, Ahmadu Bello University Teaching Hospital, Kaduna, Nigeria
}

\section{SUMMARY}

This case report appears to be first reported incident of Lebers congenital amaurosis in three siblings in Kaduna State. Genetic issues, clinical presentation, counselling, treatment and future progression of this irreversible blinding condition are discussed.

Key words: Lebers amaurosis, retinitis pigmentosa, Kaduna, Nigeria

\section{INTRODUCTION}

Retinitis pigmentosa (RP) is the generic name for a group of hereditary disorders characterized by progressive loss of photoreceptors and RPE function. The classical triad of retinitis pigmentosa is arteriolar attenuation, retinal bone spicule pigmentation and waxy disc pallor. Lebers congenital amaurosis (LCA) is the hereditary form of retinitis pigmentosa. It presents with blindness either at birth or within the first few years of life. Unfortunately, very little can be done to improve the sight of patients with Lebers. The correct diagnosis, however, is essential. First, the ophthalmologist must do a differential diagnosis, to ensure that they are not excluding a disease which might benefit from optical interventions. Second, the parents must be educated on the prognosis and natural history of the disorder. Finally, the parents should be counselled to provide special education for these children to improve the quality of their lives.

\section{CASE REPORT}

The index patient $(\mathrm{MH})$, a female aged 12 years, first presented at our clinic in 1991 at the age of 7 months. She was delivered at home after an uneventful traditional antenatal care. Her mother noticed that she could not follow objects from the age of 3 months; she also rubbed her eyes frequently. In 1991, she was the youngest of her mother's four children and the last of her father's five children. The vision of the older siblings was normal; there was no family history of blindness or ocular problems. There was no history of consanguinity. $\mathrm{MH}$ attained other developmental milestones within the adequate age range.

At first presentation (1991), MH's eyes looked essentially normal except for bilateral jerky nystagmus. The visual function was uncertain. She was examined under anaesthesia with refraction. This revealed bilateral small pink and ovoid discs with dull macular reflexes and a gross hyperopia. A 10 dioptre convex spectacle was prescribed. The patient returned for follow-up in 1997, at the age of six years. She was unable to see. Her ocular features remained the same. She was encouraged to use her glasses.

The patient defaulted on follow up until 2004 when she presented with ocular itching and foreign body sensation. She was doing well in her second year at a school for the blind (figure 1). On examination, she appeared healthy with no neurological deficits, mental/ skeletal abnormalities or deafmutism. She had no light perception bilaterally. There was bilateral right jerky nystagmus with left eye esotropia $\left(=25^{\circ}\right)$. Both pupils were small and fixed. A dilated funduscopy revealed attenuated vessels, widespread bone spicule pigmentation and pink optic discs bilaterally. Her genotype was AA and other ancillary investigations done were within normal limits. There were no facilities for electroretinogram (ERG), flourescein angiography (FA), or fundus photography.

When $\mathrm{MH}$ presented at the clinic in 2004, she had five younger siblings, two of which were also blind.

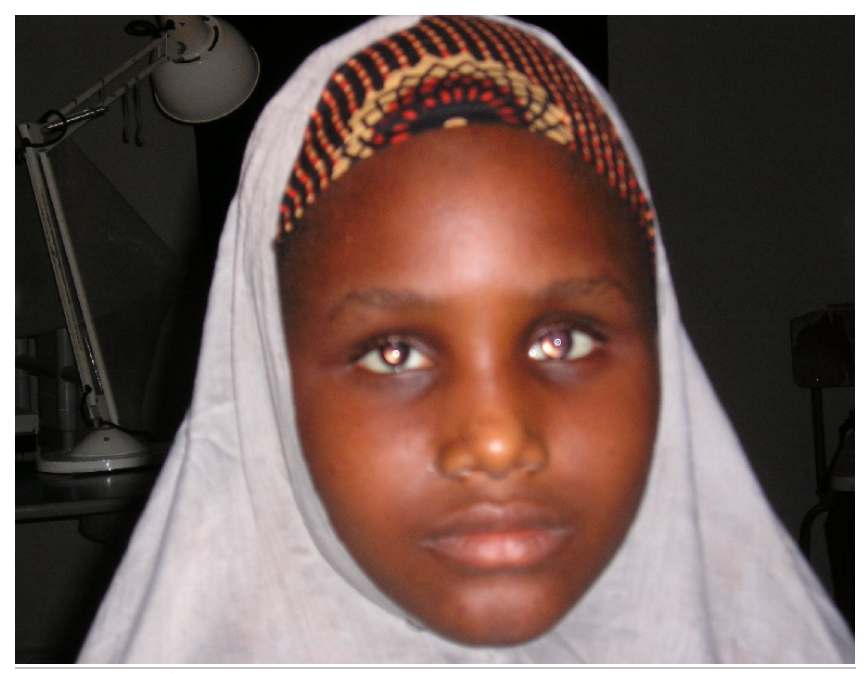

Figure 1. Index patient $\mathrm{MH}, 12$ yrs 


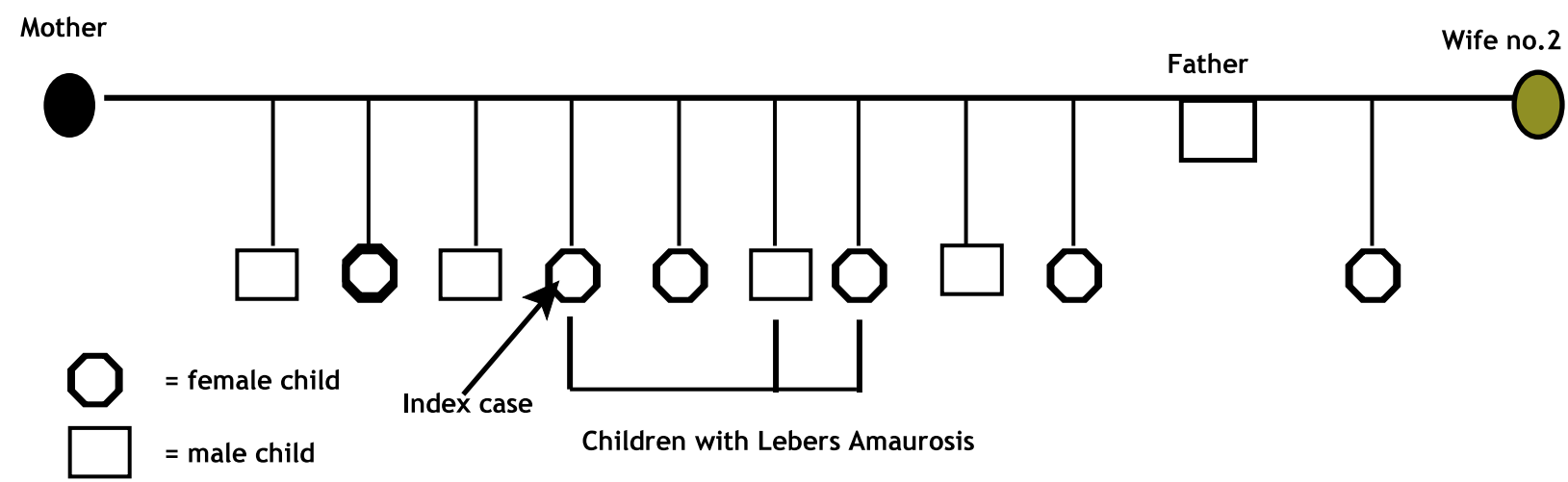

Figure 2. Diagram of MH's family line, indicating those siblings with Lebers congenital amaurosis

The second affected member of the family was $\mathrm{MB}$, a male aged seven years. He first presented in 2004 with the index case. His history was similar to that of the index case. On examination, he looked healthy (fig. 3) and had no skeletal, neurological abnormalities or deaf mutism. His vital signs were normal. Genotype was AA and all investigations similar to those done in the index case were within normal limits.

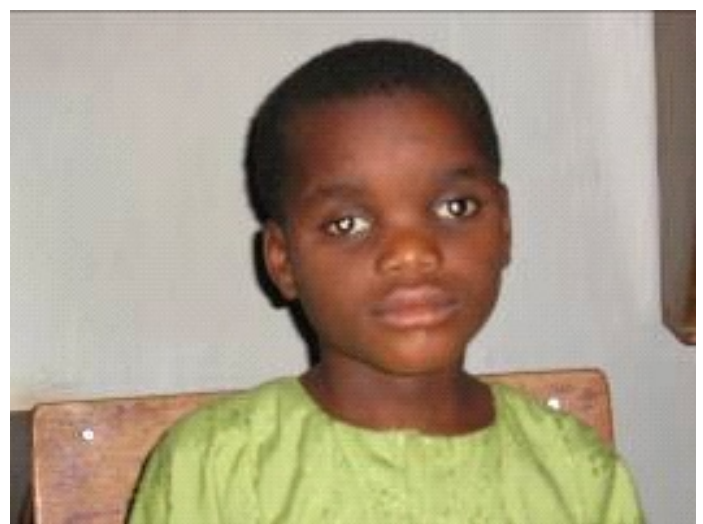

Figure 3. Patient MB, 7yrs

Ocular examination revealed deep-set eyes with bilateral jerk nystagmus to the (left) and No light perception. There was $(R)$ exotropia $\left(\approx 15^{\circ}\right)$ and the pupils were small and fixed. Dilated funduscopy revealed pink discs, VCD ratio of 0.3 with dull macular reflexes. There was bone spicule pigmentation in the mid-periphery of the retina.

The third affected family member, MS (fig. 4), was a fiveyear-old female. She first presented in 2004 with the older affected siblings. Her history was similar to that of the index case. On examination, her vital signs and all relevant investigations similar to those done in the two previous patients were within normal limits. She had doubtful light perception and constantly rubbed her eyes. There was a bilateral jerk nystagmus and alternating esotropia $\left(\approx 10^{\circ}\right)$. A dilated funduscopy revealed bilateral pink discs, dull macular reflexes and very few bone spicule pigmentary changes in the mid-retinal periphery.

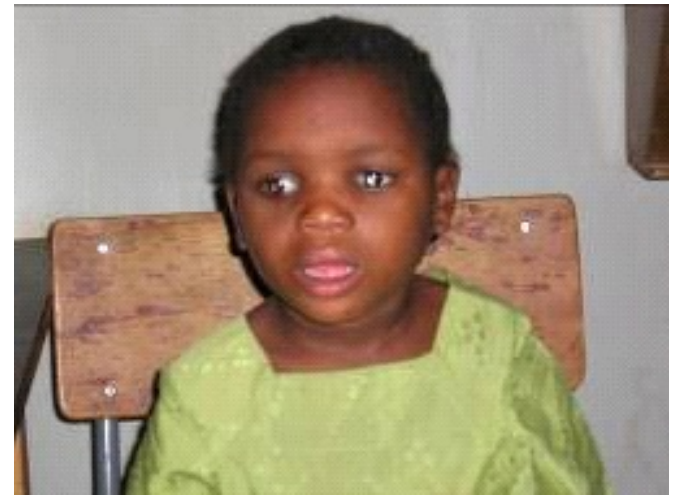

Figure 4. Patient MS, 5 yrs

Both the second and third affected family members had not commenced school for the blind due to financial constraints. Ocular examination of the mother revealed normal anterior and posterior segments. The father was not available for examination. There was no extended family history of similar eye problems. Figure 5 shows the 3 affected family members.

The condition was fully explained to the parents and they were counselled to discontinue child bearing. They were also encouraged to enroll the younger affected children in schools for the blind.

\section{DISCUSSION}

Lebers congenital amaurosis (LCA) or congenital retinitis pigmentosa accounts for $10 \%$ of congenital blindness and $5 \%$ of all inherited retinal dystrophies. ${ }^{1,2}$ It was first described by Lebers in 1869. Inheritance is mainly autosomal recessive. The 


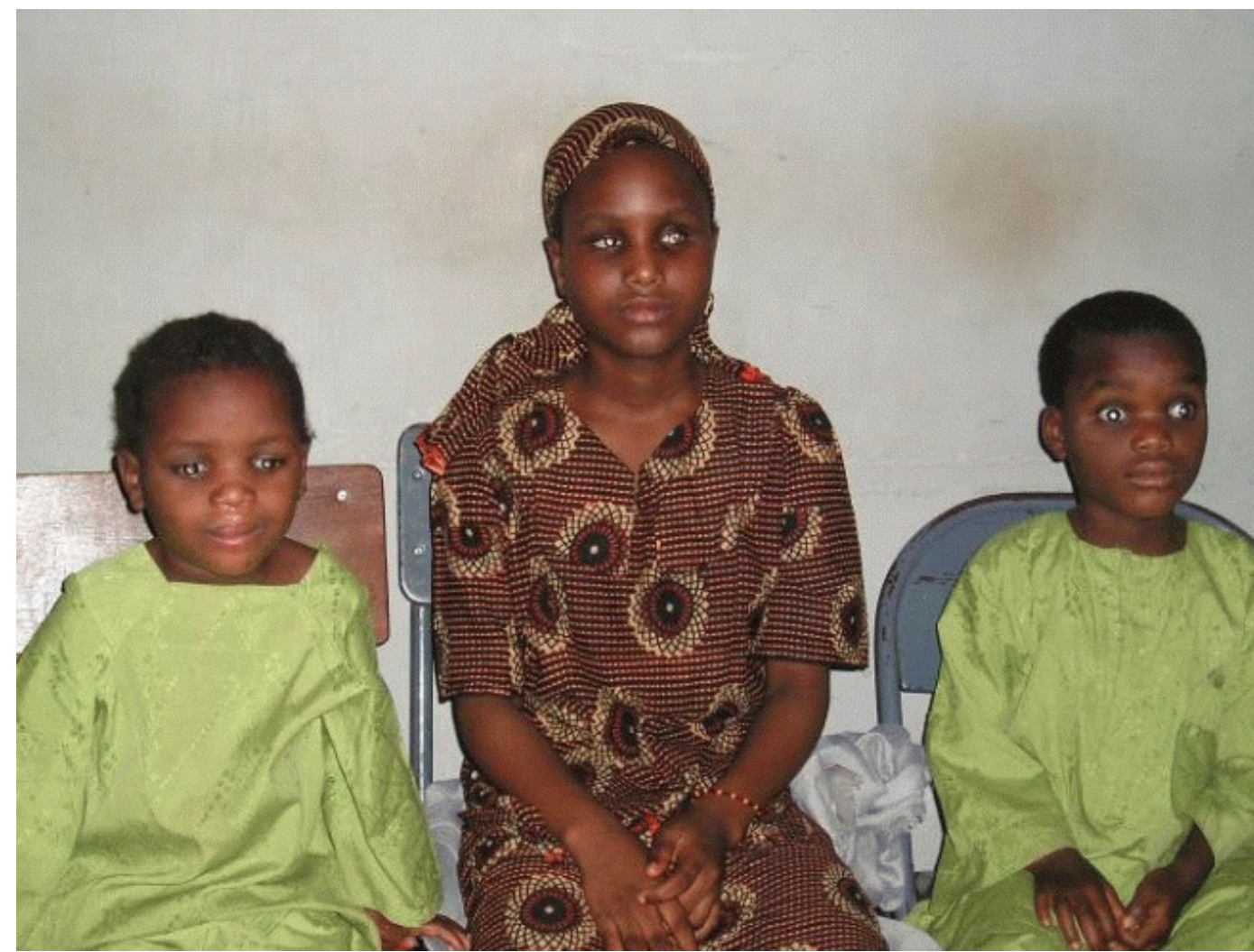

Figure 5. The three siblings with Lebers congenital amaurosis.

disease exhibits considerable clinical variation probably partly because it embraces more than one disorder. The following criteria must be fulfilled for the diagnosis to be established: blindness or severe visual impairment from birth and an absent or markedly reduced electroretinogram (ERG) in the presence of normal or nearly normal fundus.

Alstrom and Oslo ${ }^{3}$ observed that over the years gradual deterioration of any remaining vision occurs. This functional deterioration is reflected in the changing fundal appearance, and recognition of this progression is important.

\section{Genetic Considerations}

The genes responsible for RP have now been isolated for many affected families, primarily those with an austosomal dominant form. It is harder to isolate genes in recessive disorders. Nevertheless, a homozygous null mutation in the rhodopsin gene and mutations in the arrestin gene have recently been demonstrated to cause autosomal recessive RP. In LCA, impaired development or early degeneration of photoreceptors is believed to be related to a mutation on chromosome 17. This leads to impaired production of retinal guanylate cyclase. ${ }^{4}$ In addition, genes that cause associated systemic syndromes like Ushers and Bardet Biedl have also been mapped. Investigators are actively pursuing the gene associated with various forms of LCA.

\section{Clinical Presentation}

There are four clinical conditions of congenital RP. Typical LCA is the best-known and the commonest form of Lebers. It is autosomal recessive and develops within a few months of life. Patients present with an inability to see in infancy. At the early stages of the disease, the fundi appear normal, but with time pigmentary deposits appear and generalized retinal changes develop. Sufferers are highly hyperopic with cataracts. ${ }^{5,6}$ Invariably a searching nystagmus develops by the second year of life. A few present with night blindness and photoaversion. ${ }^{7}$ Electroretinogram shows flat or minimal response. Many patients with LCA have been observed to rub or poke their eyes (oculodigital reflex).

A second clinical presentation could be congenital retinitis pigmentosa with macular colobomas and severe hypermetropia. These are autosomal recessive.

Complicated LCA could also present. In this group the congenital retinitis pigmentosa is associated with systemic or neurological abnormalities. ${ }^{9}$ The following syndromes are common in complicated Lebers: Zellwegers, Saldino-Mainzer, among others.

The least common clinical presentation is autosomal dominant inherited. Sufferers are affected only in childhood developing nystagmus and severe visual field loss. Some useful vision may be retained till thirty years of age. Retinal pigmentary changes develop later. 


\section{Differential Diagnosis}

The differential diagnosis of LCA is important because the prognostic implications of the disease are serious and an error in diagnosis can be devastating in terms of psychological impact. Retinal atrophy and spiculed pigmentary degeneration are nonspecific findings that can result from infections, e.g. syphilis; inflammations, e.g. uveitis; toxicity, e.g. chloroquine; or a variety of systemic metabolic disorders.

Also, a variety of systemic and some congenital syndromes include as juvenile Batten's disease (neuronal ceroid lipofuscinosis), Bassen-Kornzweig syndrome (abetalipoproteinaemia), Refsum's syndrome/phytanic acid storage disease, Gyrate atrophy of the choroid and retina with hyperornithinaemia, Bardet-Biedl syndrome and Usher's syndrome

Friedreich's ataxia may be associated with pigmentary degeneration of the retina. Cystinosis and oxalosis are rare conditions with childhood pigmentary disturbances.

The above list is not exhaustive for LCA differentials. Any infant with retinal dysfunction and a low ERG should be carefully screened for congenital syndromes and metabolic disorders that affect the retina before being diagnosed with LCA.

\section{Management and Therapy}

Patients with newly-diagnosed LCA require counselling to help them understand the disease, its genetics and prognosis, and to deal with functional deficits of poor acuity, narrowed visual fields and blindness. Also, the benefits of rehabilitation are therapeutic.

Various nutritional supplements have been investigated as therapy for RP and one or more of these may eventually prove to have merit. One large study concluded that high daily doses of vitamin A palmitate $(15,000 \mathrm{iu} /$ day) can slow the progression of RP by about $2 \%$ per year. No conclusive epidemiological evidence proves that antioxidant supplements are effective against RP.

Light is considered to be a source of stress and age-related damage in the retina as well as a possible accelerator of dystrophic injury. Protection from high levels of light exposure in combination with a brimmed hat is probably good for dystrophy patients.

Molecular biology may, in the future, provide a means of modifying the course of RP and indeed LCA. It may become possible to regulate or replace the diseased genes or to use genetic information to employ conventional therapy more effectively. Progress is also being made towards transplantation of retinal cells and the use of humoral factors to slow secondary degenerative changes.

\section{Counselling}

Since patients with congenital Lebers amaurosis are invariably blind very early in life, they benefit most from visual rehabilitation. Enrolling them in schools for the blind can enhance their standard of living. This will enable them learn to read Braille as well as learn a trade.

Parents of sufferers should also be counselled against further procreation.

\section{REFERENCES}

1. Deutman A. A rod-cone dystrophy: Primary hereditary pigmentary retinopathy, retinitis pigmentosa. In Krill (ed.). Hereditary Retinal and Choroidal Disease. Hagerstown, MD, Harper and Row, 1977; 522-526.

2. Perault I, Rozet JM, Caluas P et al. Retinal-specific guanylate cyclose gene mutations in Lebers congenital amaurosis. Nature Genet 1996; 14: 461.

3. Alstron, $\mathrm{CH}$ and Olson, $\mathrm{O}$. Heredo-retinopathia congenitatis monohybrida recessiva autosomalis. Hereditas 43: 1-177.

4. Camuzat A, Rozet JM, Dollfas $\mathrm{H}$ et al. A gene for Lebers congenital amaurosis maps to chromosomes 17p. Hum Mol Genet 1995; 4: 1447.

5. Dagl LR, Leyes MJ, Hansen RM, Fulton AB. Hyperopia in complicated Lebers congenital amaurosis. Arch Ophthalmic 1990; 108: 709.

6. Schroeder R, Mets MB, Maumenee IH. Lebers congenital amaurosis: Retrospective review of 43 cases and a new fundus finding in two cases. Arch Ophthalmol 1987; 105: 356.

7. Traboulsi EI, Maumenee IH. Photaversion in Lebers congenital amaurosis. Ophthalmic Genet 1995; 16: 27.

8. Philip CI, Griffiths DL. Maular coloboma and skeletal abnormality. Br J Ophthalmol 1996; 53: 346.

9. Vaizey MJ, Sanders MD, Wyban KC et al. Neurological abnormalities in congenital amaurosis of Leber. Arch Dis Child 1977; 52: 399.

10. Carr RE. Abetalipoproteinaemia and the eye. In: The Eye and Inborn Errors of Metabolism. Birth Defects XXII No. 3. Bergsma D, Bron AJ and Cotlier E, eds. New York: Alan R. Liss. 1976.

11 Hansen E, Bachen NI, Flage T. Refsum's disease. Acta Ophthalmologica 1979; 57: 899-913. 